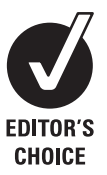

CHOICE

\title{
Anti-interleukin-5 antibody treatment (mepolizumab) in active eosinophilic oesophagitis: a randomised, placebo-controlled, double-blind trial
}

\author{
- Additional figures, tables and \\ supplementary information are \\ published online only at http:// \\ gut.bmi.com/content/vol59/ \\ issue1 \\ 1 Department of \\ Gastroenterology, Kantonsspital, \\ Olten, Switzerland; ${ }^{2}$ Institute of \\ Pharmacology, University of \\ Bern, Bern, Switzerland; \\ ${ }^{3}$ Allergic Diseases Research \\ Laboratory, Mayo Clinic, \\ Rochester, Minnesota, USA; \\ ${ }^{4}$ Institute for Clinical Pathology \\ Viollier, Basel, Switzerland; \\ ${ }^{5}$ Department of \\ Gastroenterology, University \\ Hospital Basel, Basel, \\ Switzerland; ${ }^{6}$ GlaxoSmithKline, \\ Research Triangle Park, North \\ Carolina, USA: \\ ${ }^{7}$ GlaxoSmithKline, Stockley \\ Park, Uxbridge, UK
}

Correspondence to:

Professor H-U Simon, Institute of Pharmacology, University of

Bern, Friedbuehlstrasse 49, CH3010 Bern, Switzerland; hus@ pki.unibe.ch

Revised 13 July 2009 Accepted 17 July 2009

Published Online First

12 October 2009

\section{A Straumann, ${ }^{1}$ S Conus, ${ }^{2}$ P Grzonka, ${ }^{2}$ H Kita, ${ }^{3}$ G Kephart, ${ }^{3}$ C Bussmann, ${ }^{4}$ C Beglinger, ${ }^{5}$ D A Smith, ${ }^{6}$ J Patel, ${ }^{7}$ M Byrne, ${ }^{7}$ H-U Simon ${ }^{2}$}

\section{ABSTRACT}

Objective: Eosinophilic oesophagitis (EoO) is a clinicopathological condition defined by proton pump inhibitorrefractory oesophageal symptoms combined with oesophageal eosinophilia. The pharmacodynamic effect of mepolizumab (a humanised anti-interleukin-5 monoclonal antibody) in E00 was evaluated.

Methods: Eleven adults with active Eo0 ( $>20$ peak eosinophil number/high power field (hpf) and dysphagia) were randomised to $750 \mathrm{mg}$ of mepolizumab $(\mathrm{n}=5)$ or placebo $(n=6)$ and received two intravenous infusions, 1 week apart. Those not in complete remission $1<5$ peak eosinophil number/hpf) after 8 weeks received two further doses 4 weeks apart, 1500 mg of mepolizumab or placebo. The effect of mepolizumab was assessed clinically, endoscopically, histologically, and via blood and tissue biomarkers.

Results: As assessed by immunofluorescence, a marked reduction of mean oesophageal eosinophilia $(p=0.03)$ was seen in the mepolizumab group (-54\%) compared with the placebo group $(-5 \%) 4$ weeks after initiation of treatment. No further reduction of eosinophil numbers was observed in response to the two additional infusions in either group. Mepolizumab reduced tenascin $C$ $(p=0.033)$ and transforming growth factor $\beta 1$ $(p=0.05)$ expression in the oesophageal epithelial laye 13 weeks after initiation of treatment. Clinically, limited improvement of symptoms was seen, although a trend was seen between 4 and 13 weeks after initiation of mepolizumab treatment. Mepolizumab was well tolerated. Conclusions: Mepolizumab significantly reduced eosinophil numbers in oesophageal tissues in adult patients with active EoO, and changes in the expression of molecules associated with oesophageal remodelling were reversed. Minimal clinical improvement was achieved in a subgroup of patients with EoO. Mepolizumab had an acceptable safety profile, even at the high $1500 \mathrm{mg}$ dose level.

Trial registration number: NCT00274703

Eosinophilic oesophagitis (EoO) is an emerging disease with a constantly increasing prevalence. ${ }^{1-3}$ It represents a chronic inflammatory disorder with narrowing or stricture of the oesophagus. ${ }^{4} \mathrm{EoO}$ and gastro-oesophageal reflux disease (GORD) may share common clinical features, but in EoO symptoms and signs do not respond to proton pump inhibitors (PPIs). Moreover, EoO can be distinguished from GORD by a more prominent oesophageal eosinophilia ( $>20$ peak eosinophil number per high power field (hpf)), often affecting the entire oesophagus. ${ }^{4}{ }^{5}$ Adult EoO is considered to be a T helper 2 (Th2)-type allergic disease, ${ }^{6}$ whereby aeroallergens play a key pathogenic role. The inflammation in the gastrointestinal tract is restricted to the oesophagus and does not affect the stomach, small intestine and colon. ${ }^{6}$ However, patients with EoO may also suffer from additional allergic diseases of the respiratory tract.'

Patients with EoO present with difficulty of swallowing, food regurgitation and vomiting, as well as with chest and upper abdominal pain. ${ }^{8}$ Studies analysing the natural history of adult EoO suggested that the chronic inflammation may lead to structural changes in the oesophagus, with subepithelial fibrosis and a loss of the mucosal elasticity resulting in impaired function. ${ }^{9}$ In an experimental mouse model, it has recently been shown that oesophageal remodelling develops as a consequence of interleukin-5 (IL-5)-induced eosinophilia. ${ }^{10}$ Therefore, strategies to reduce eosinophilic inflammation within the oesophagus of patients with EoO appear to be promising.

Today, standard recommendations for pharmacological EoO treatment mainly include systemic and topical corticosteroids, although most of the published studies were carried out in children. ${ }^{11-17}$ However, corticosteroid treatment is limited by the occurrence of steroid dependency, steroid resistance and corticosteroid-inherent side effects. ${ }^{11}$ Taken together, although the past decade has witnessed the recognition of $\mathrm{EoO}$ as a new disease entity, there is a need to establish therapeutic options for this disease, in particular for patients with severe EoO that do not respond satisfactorily to corticosteroids.

Mepolizumab is a fully humanised anti-IL-5 monoclonal antibody, which has been shown to be clinically beneficial in patients suffering from eosinophilic diseases, such as hypereosinophilic syndrome, ${ }^{18}$ eosinophilic dermatitis, ${ }^{19}$ eosinophilic sinus disease ${ }^{20}$ and eosinophilic asthma. ${ }^{21} 22$ Recently, mepolizumab was administered to four patients with adult EoO in an open label trial and the treatment was associated with an impressive reduction of both oesophageal eosinophilia and symptoms. ${ }^{23}$ We conducted a randomised, double-blind, placebo-controlled trial of mepolizumab for adult patients with EoO. Our aim was to evaluate the effects of this antibody on oesophageal eosinophilia and symptoms in the absence of any other antieosinophil treatment. Besides eosinophils, we analysed several other cells and soluble factors in the inflamed oesophagus that are currently believed to participate in EoO pathogenesis 


\section{MATERIALS AND METHODS}

\section{Patients}

The patients were recruited between December 2005 and May 2006 with the last follow-up completed by March 2007 at a single gastroenterology clinic in Olten, Switzerland. Included were patients of 18 years of age or older suffering from active EoO with a history of at least one episode of dysphagia per week in the 4 weeks prior to the start of study medication and a peak oesophageal eosinophilia of $>20$ eosinophils per hpf (peak eosinophil density). All patients had experienced an inadequate response to topical and/or systemic corticosteroid treatment or a history of relapse of clinical symptoms on withdrawal of EoO treatment, and were selected from the Swiss EoO database, which includes patients from the German-speaking part of Switzerland with $\sim 5$ million inhabitants. At the beginning of the recruitment phase, this cohort encompassed a total of 218 adolescent and adult patients with previously confirmed diagnosis of EoO. Each patient had documented evidence of exclusion of other causes of oesophagitis and other causes of oesophageal or blood eosinophilia (ie, hypereosinophilic syndromes, eosinophilic gastroenteritis and parasitic infection). GORD was excluded in all patients by pretreatment with PPIs in standard dosages plus negative endoscopy for signs of reflux disease, and by $\mathrm{pH}$ monitoring (optional). No antieosinophil treatment (ie, systemic or topical corticosteroids, mast cell stabilisers, leukotriene antagonists or immunosuppressants) was permitted for at least 6 weeks prior to the start of mepolizumab treatment. Exclusion criteria were any condition with the risk of requiring oesophageal dilatation during the course of the study, a history of seasonal exacerbation of EoO symptoms expected to coincide with the period of investigation, active Helicobacter pylori infection and any unstable medical conditions. Also excluded were patients using mast cell stabilisers, leukotriene receptor antagonists or immunosuppressive/immunomodulatory agents, those with a history of allergic reactions to previous antibody treatment, or any previous treatment with an anti-IL-5 antibody or any other biopharmaceutical agent. Female patients were excluded if pregnant or breastfeeding, or if they were not taking adequate contraceptive measures. The study was conducted to ICH/GCP guidelines and approved by the Ethical Committee of the Kantonsspital Olten, Olten, and the Swissmedic regulatory authority, Bern, Switzerland. Written informed consent was obtained from all patients.

\section{Study design}

This was a randomised, double-blind, placebo-controlled study to evaluate the ability of mepolizumab to reduce peak oesophageal eosinophilia to $<5$ eosinophils/hpf as assessed by histology in adults with active EoO. Eligible patients underwent a screening assessment of physical examination and blood sampling for differential count and other tests to eliminate exclusion criteria. Any current antieosinophil treatment was discontinued and patients were directed to avoid any changes in their feeding habits during the entire study period. During the screening phase, patients commenced daily diary completion of their EoO symptoms. At the end of the screening phase, which lasted at least 4 weeks, patients underwent oesophagogastroduodenoscopy (OGD), and biopsies as well as blood were taken as the baseline assessment. Patients who met the inclusion/ exclusion criteria were enrolled by the principal investigator and randomised equally to either active treatment or placebo in accordance with a computer-generated randomisation schedule supplied by the sponsor. Treatment was initiated with two intravenous infusions of either $750 \mathrm{mg}$ of mepolizumab or placebo on days 0 and 7, administrated over $30 \mathrm{~min}$. Four weeks after the first infusion, patients underwent repeat OGD and all other examinations as performed during baseline assessment. The study was designed such that any patient who had responded to treatment, defined by a reduction in peak oesophageal eosinophil counts to $<5 / \mathrm{hpf}$, progressed into the short-term follow-up (STFU) phase, which lasted 8 weeks. Those patients who had not responded and had no treatmentrelated safety concerns received two further infusions of either $1500 \mathrm{mg}$ of mepolizumab or placebo, according to their original treatment allocation, given 4 weeks apart at weeks 5 and 9, respectively. Four weeks after the last infusion (week 13), patients again underwent OGD, repeat biopsy and blood tests as done at baseline. Patients then progressed to the STFU phase for 8 weeks, such that all patients were assessed 21 weeks after the start of treatment for antimepolizumab antibodies and blood eosinophil counts in particular. Patients then continued into the long-term follow-up (LTFU) phase, which ended with an assessment at 34 weeks after the last infusion (week 43). An outline of the study design is shown in fig 1 .

\section{Study treatment}

Mepolizumab (GlaxoSmithKline, Greenford, UK) was administered by intravenous infusion at a dose of $750 \mathrm{mg}$ diluted in $150 \mathrm{ml}$ of $0.9 \%$ sodium chloride solution for the first two infusions. The $750 \mathrm{mg}$ dose was selected because it had been shown efficacy in reducing eosinophil numbers and regarding clinical improvement in $\mathrm{EoO}^{23}$ and other eosinophilic-driven diseases. ${ }^{18-22}$ It was decided for this exploratory study that, if patients had not responded to $750 \mathrm{mg}$, a higher dose might be required. Non-responding patients received two further infusions of $1500 \mathrm{mg}$ diluted in $250 \mathrm{ml}$ of saline 4 weeks apart. Patients allocated to the placebo arm received the corresponding
Figure 1 Study design. STFU, shortterm follow-up 12 weeks after the last infusion. LTFU, long-term follow-up 34 weeks after the last infusion. Note that the placebo group received $150 \mathrm{ml}$ of $0.9 \%$ sodium chloride solution instead of mepolizumab. Due to the fact that none of the patients reached the primary end point of the study, all patients followed the path of the non-responders (thick arrows).

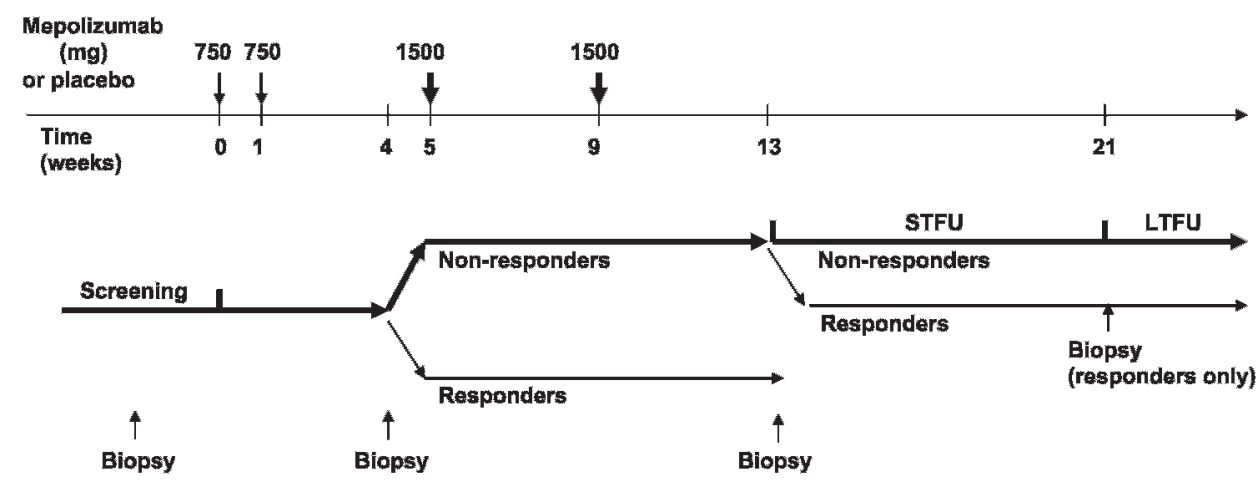


infusions of saline only. To keep the treatment blinded, the infusions were made up by an independent pharmacist who obtained the treatment allocation via a telephonic randomisation system. Of the study personnel, only the pharmacist, responsible for the preparation of infusions, had access to the treatment assignments. For each visit, a random visit code was generated and persons involved in assessing tissue samples and blood parameters received only this visit code. In order to maintain the blind, the investigator did not have access to the eosinophil count data until all subjects had completed the STFU assessment.

\section{Clinical evaluation}

Symptoms were assessed by means of a previously published, slightly modified, non-validated score focusing on oesophagusrelated symptoms. ${ }^{9}$ The duration and intensity of the dysphagia events were recorded. Patients started daily recording of the 4item questionnaire 4 weeks before randomisation and throughout the entire study period. In addition, patients were asked to assess whether they had experienced any global improvement in EoO symptoms from baseline at week 4,13 and at the STFU visit (week 21).

OGDs were performed in all patients by one single, boardcertified gastroenterologist (AS) who was blinded to the treatment allocation. Endoscopic findings were graded by means of a simple overall score: absent, minor (fine nodules, fine whitish reticular structures, furrows), moderate (bright white scale- or plaque-like structures, corrugated rings) or severe (mucosal lesions, fixed stenosis). ${ }^{?}$

\section{Tissue sampling and histological analysis}

As the inflammatory pattern in EoO is often very patchy, ${ }^{82}$ a systematic and standardised approach was used for tissue sampling. Four specimens, one from each quadrant, were taken endoscopically from both the proximal and lower halves of the oesophagus. The biopsy samples were identified by a random code to conceal the patient identity, treatment allocation and visit sequence. The specimens were immediately fixed in $4 \%$ formaldehyde solution and afterwards embedded in paraffin. Sections $(4 \mu \mathrm{m})$ were cut from the paraffin blocks and stained for light microscopic and immunofluorescence examinations.

The histological examination was performed by an independent, board-certified gastroenterological-pathologist (CB). For each of the eight biopsy specimens, all levels were surveyed and the eosinophils were counted in 10 consecutive hpfs (Zeiss Axiophot, Jena, Germany: Plan-Neofluar 40, ocular magnification $\times 10$, area of hpf $\left.0.3072 \mathrm{~mm}^{2}\right)$ such that 80 counts were made $(10 \times 8$ specimens) for each patient at each time point, and the peak, mean and range of eosinophil counts were derived.

\section{Safety assessments}

Patient safety evaluations included physical examination, measurement of weight, vital signs, 12-lead ECG, pregnancy testing, clinical laboratory testing (haematology, including white cell differential counts, and clinical chemistry) and recording of adverse events. In addition, specific assessments were included at the follow-up visits to detect worsening symptoms and/or signs of EoO on withdrawal of treatment (rebound phenomenon). Furthermore, patients were monitored in the clinic during and for 30 min after each infusion. Specifically, any signs or symptoms suggestive of hypersensitivity reaction (pruritus, urticaria, skin rash, angio-oedema, stridor or wheezing)
Table 1 Patient characteristics

\begin{tabular}{lcc}
\hline & Mepolizumab (n = 5) & Placebo (n = 6) \\
\hline Mean age (years) & 32.4 & 34.0 \\
Males (\%) & 80 & 50 \\
Caucasians (\%) & 100 & 100 \\
Mean weight (kg) & 74.0 & 75.3 \\
Duration of E00 (years) & 5.32 & 5.28 \\
Age of onset (years) & 26.6 & 28.7 \\
Atopic disease at screen & & \\
$\quad$ Asthma (n (\%)) & $1(20 \%)$ & $2(33 \%)$ \\
Eczema (n (\%)) & $1(20 \%)$ & 0 \\
Food allergy (n (\%)) & $1(20 \%)$ & 0 \\
$\quad$ Rhinitis (n (\%)) & $4(80 \%)$ & $4(67 \%)$ \\
Mean peak oesophageal & 201 & 202 \\
eosinophils at screening (per hpf) & &
\end{tabular}

Eo0, eosinophilic oesophagitis; hpf, high power field.

or anaphylaxis (hypotension or tachycardia) would have resulted in appropriate clinical management of the reaction.

\section{Biomarker assessment}

As this was the first placebo-controlled study of a treatment for adult EoO, evaluation of a number of exploratory biomarkers was included, first to provide supportive evidence of the effect of mepolizumab on the eosinophil count data as assessed by histology, and secondly potentially to identify surrogate markers of mepolizumab activity that might be used in subsequent studies. The assays used in this study are described in the supplementary information online and were partially described earlier. ${ }^{25-29}$

\section{Statistics}

The primary end point of the study was the proportion of responders (patients with $<5$ eosinophils per hpf) following treatment with mepolizumab or placebo. No formal sample size estimate was performed; it was planned for 10 patients to be randomised; 5 to mepolizumab and 5 to placebo. The main analyses were performed on the intent-to-treat (ITT) population, defined as all patients who were randomised and received

Table 2 Previous treatments for eosinophilic oesophagitis and reasons for discontinuation

\begin{tabular}{|c|c|c|c|}
\hline $\begin{array}{l}\text { Reason for } \\
\text { treatment } \\
\text { discontinuation }\end{array}$ & Treatment & $\begin{array}{l}\text { Mepolizumab } \\
(n=5) \text { n (\%) }\end{array}$ & $\begin{array}{l}\text { Placebo }(n=6) n \\
(\%)\end{array}$ \\
\hline \multirow[t]{6}{*}{ Lack of efficacy } & Dilatation & $1(20 \%)$ & 0 \\
\hline & $\begin{array}{l}\text { Leukotriene receptor } \\
\text { antagonist }\end{array}$ & $1(20 \%)$ & $1(17 \%)$ \\
\hline & $\begin{array}{l}\text { Inhaled/swallowed } \\
\text { steroids }\end{array}$ & $3(60 \%)$ & $3(50 \%)$ \\
\hline & Systemic steroids & 0 & $1(17 \%)$ \\
\hline & Elemental diet & 0 & $1(17 \%)$ \\
\hline & $\begin{array}{l}\text { Other } \\
\text { immunomodulators } \\
\text { (6-mercaptopurine) }\end{array}$ & 0 & $1(17 \%)$ \\
\hline \multirow{4}{*}{$\begin{array}{l}\text { Treatment-related } \\
\text { adverse effects }\end{array}$} & Dilatation & $1(20 \%)$ & $3(50 \%)$ \\
\hline & $\begin{array}{l}\text { Leukotriene receptor } \\
\text { antagonist }\end{array}$ & $1(20 \%)$ & $1(17 \%)$ \\
\hline & $\begin{array}{l}\text { Inhaled/swallowed } \\
\text { steroids }\end{array}$ & $1(20 \%)$ & $3(50 \%)$ \\
\hline & Systemic steroids & $1(20 \%)$ & 0 \\
\hline \multirow{2}{*}{$\begin{array}{l}\text { Patient choice to } \\
\text { withdraw from } \\
\text { treatment }\end{array}$} & Dilatation & $1(20 \%)$ & 0 \\
\hline & Systemic steroids & $1(20 \%)$ & 0 \\
\hline
\end{tabular}




\section{Blood eosinophils [per $\mathrm{mm}^{3}$ ]}

Placebo

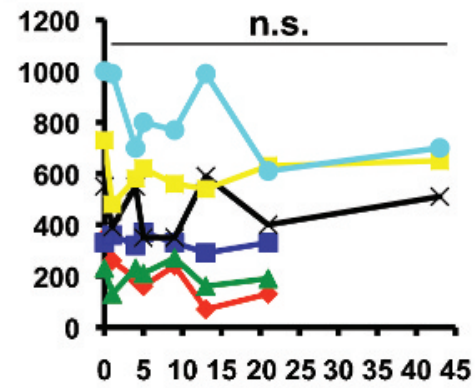

\section{Mepolizumab}

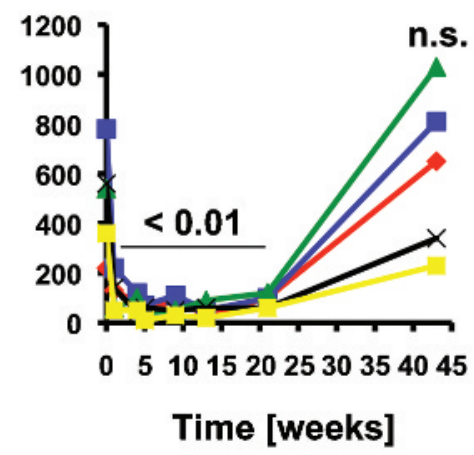
Peak eosinophils
[per hpf]

\section{Mean eosinophils} [per hpf]
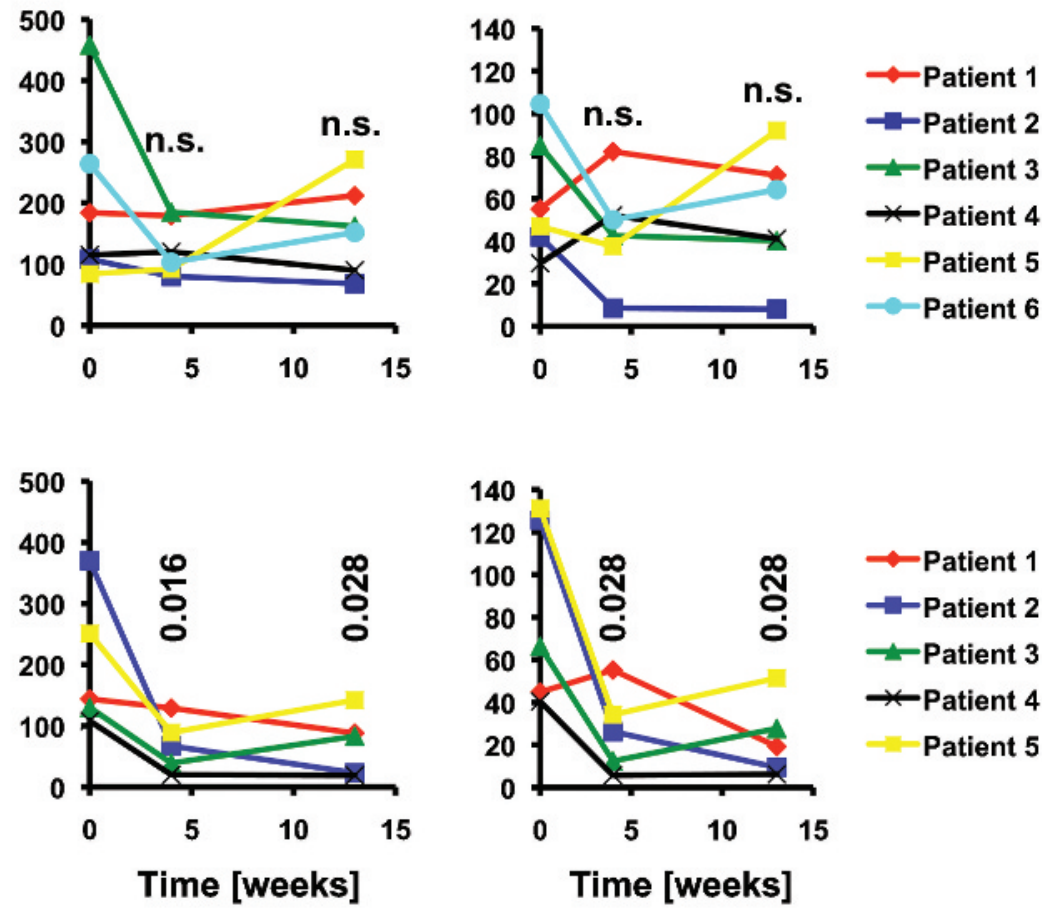

Figure 2 Reduction of eosinophil numbers in blood and in the oesophageal epithelial layer by mepolizumab in patients with eosinophilic oesophagitis. Single patient data are presented in both the placebo (upper panels) and mepolizumab (lower panels) groups. $\mathrm{p}$ Values are indicated. hpf, high power field.

at least one dose of mepolizumab. In the figures and tables, we present means with standard deviation (SD) or with standard errors (SEM). Indicated statistical differences between mean levels from posthoc analysis were calculated using MannWhitney $U$ test. A p value $<0.05$ was considered statistically significant.

\section{RESULTS}

\section{Patient screening and demographics}

Thirteen patients were screened for participation in the study, of which 11 were randomised to treatment; 5 to mepolizumab and 6 to placebo. Both of the screening failures were due to a baseline peak oesophageal eosinophil count <20/hpf. All 11 patients completed the study up to week 21. Three subjects discontinued the study after week 21 . Each of these patients (1 mepolizumab; 2 placebo) developed worsening EoO that required alternative treatment. The disposition of the patients is shown in supplementary fig 1.

The baseline characteristics of the patients (table 1) illustrate that the treatment groups were largely similar. There were no differences in age, body weight, age of onset and duration of $\mathrm{EoO}$, but there were a higher proportion of males in the mepolizumab group (80\%) compared with placebo (50\%). The mean baseline peak oesophageal eosinophil counts were similar in both groups, $\sim 200 / \mathrm{hpf}$, but the mean eosinophil count was higher in the mepolizumab group (82/hpf) compared with the placebo group (61/hpf) (table 3$)$. Each patient reported having experienced dysphagia and episodes of food impaction before entering the study. Moreover, all patients rated difficulty in swallowing as their most bothersome EoO symptom at the study start. All but one patient in the placebo group reported
Table 3 Oesophageal tissue infiltration by inflammatory cells

\begin{tabular}{|c|c|c|c|c|c|}
\hline & Visit & Mean & SD & $\begin{array}{l}\text { Change } \\
\text { from } \\
\text { screen } \\
(\%)\end{array}$ & p Value \\
\hline \multicolumn{6}{|l|}{$\begin{array}{l}\text { Mean eosinophils per hpf } \\
\left(\mathrm{ECP}^{+} \text {cells) }\right.\end{array}$} \\
\hline \multirow[t]{3}{*}{ Mepolizumab $(n=5)$} & Screening & 73.21 & 50.57 & & \\
\hline & Week 4 & 33.83 & 22.82 & -54 & 0.030 \\
\hline & Week 13 & 32.72 & 28.32 & -55 & 0.011 \\
\hline \multirow[t]{3}{*}{ Placebo $(n=6)$} & Screening & 56.71 & 33.43 & & \\
\hline & Week 4 & 53.99 & 24.51 & -5 & NS \\
\hline & Week 13 & 52.68 & 28.75 & -7 & NS \\
\hline \multicolumn{6}{|l|}{$\begin{array}{l}\text { T cells per hpf }\left(\mathrm{CD}^{+}\right. \\
\text {cells) }\end{array}$} \\
\hline \multirow[t]{3}{*}{ Mepolizumab $(n=5)$} & Screening & 69.95 & 19.19 & & \\
\hline & Week 4 & 67.86 & 11.30 & -3 & NS \\
\hline & Week 13 & 67.86 & 21.94 & -3 & NS \\
\hline \multirow[t]{3}{*}{ Placebo $(n=6)$} & Screening & 63.89 & 18.06 & & \\
\hline & Week 4 & 66.99 & 17.28 & +5 & NS \\
\hline & Week 13 & 66.56 & 23.65 & +4 & NS \\
\hline \multicolumn{6}{|l|}{$\begin{array}{l}\text { Mast cells per hpf } \\
\text { (tryptase }{ }^{+} \text {cells) }\end{array}$} \\
\hline \multirow[t]{3}{*}{ Mepolizumab $(n=5)$} & Screening & 25.41 & 15.18 & & \\
\hline & Week 4 & 23.77 & 11.02 & -6 & NS \\
\hline & Week 13 & 20.57 & 10.62 & -19 & NS \\
\hline \multirow[t]{3}{*}{ Placebo $(n=6)$} & Screening & 23.02 & 13.19 & & \\
\hline & Week 4 & 26.67 & 12.33 & +15 & NS \\
\hline & Week 13 & 22.59 & 13.18 & -2 & NS \\
\hline
\end{tabular}

$\mathrm{ECP}$, eosinophil cationic protein; hpf, high power field; NS, non-significant. 
Figure 3 Improvement of dysphagia. The proportion of days with difficulties in swallowing solid food were averaged 4 weeks before screening and over 7 days prior to each visit (results of a questionnaire). (A) Individual patient data. In each group, 3 patients had dysphagia almost every day and did not change. (B) Mean patient data. Red, mepolizumab; black, placebo. The small improvements in both patient groups were statistically non-significant.
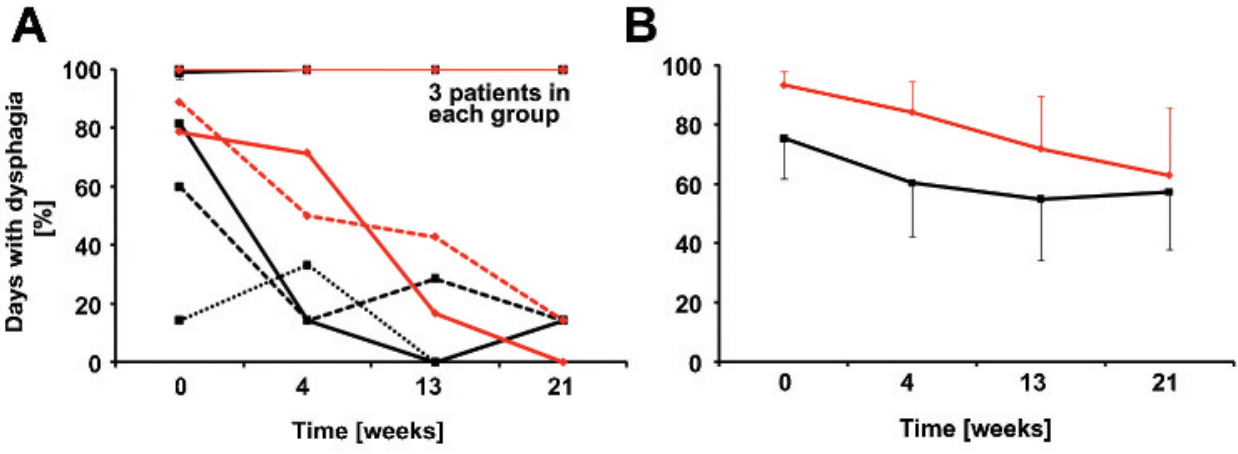

retrosternal pain, but none reported pain in the upper abdomen or vomiting at the screening visit.

Concomitant treatment for EoO was not permitted during the study. Patients had discontinued a similar range of prior EoO treatments either due to lack of efficacy or due to treatment-related adverse effects (table 2) in both groups. Two patients of the placebo group had no record of prior EoO treatment.

\section{Antieosinophil efficacy}

No patient in either treatment group achieved the primary end point of the study - that is, a reduction of peak oesophageal eosinophil counts to $<5 / \mathrm{hpf}$. Additionally, lesser thresholds of $<10$ or $<15$ eosinophils/hpf were not seen in any patient. However, as assessed by histology, a marked reduction in eosinophil counts was observed in the mepolizumab group at weeks 4 and 13. The reductions concern both peak $(-66 \%$, week $4 ;-65 \%$, week 13$)$ and mean eosinophil numbers $(-67 \%$,

Table 4 Clinical improvement in eosinophilic oesophagitis

\begin{tabular}{|c|c|c|c|}
\hline Visit & $\begin{array}{l}\text { Global } \\
\text { improvement }\end{array}$ & $\begin{array}{l}\text { Mepolizumab } \\
(n=5) \text { n (\%) }\end{array}$ & $\begin{array}{l}\text { Placebo }(n=6) n \\
(\%)\end{array}$ \\
\hline \multirow[t]{6}{*}{ Week 4} & Much worse & 0 & $1(17 \%)$ \\
\hline & Minimally worse & 0 & $1(17 \%)$ \\
\hline & No change & $2(40 \%)$ & $1(17 \%)$ \\
\hline & Minimally improved & $2(40 \%)$ & $1(17 \%)$ \\
\hline & Much improved & $1(20 \%)$ & $1(17 \%)$ \\
\hline & $\begin{array}{l}\text { Very much } \\
\text { improved }\end{array}$ & 0 & $1(17 \%)$ \\
\hline \multirow[t]{6}{*}{ Week 13} & Much worse & 0 & 0 \\
\hline & Minimally worse & 0 & 0 \\
\hline & No change & $3(60 \%)$ & $5(83 \%)$ \\
\hline & Minimally improved & 0 & $1(17 \%)$ \\
\hline & Much improved & $2(40 \%)$ & 0 \\
\hline & $\begin{array}{l}\text { Very much } \\
\text { improved }\end{array}$ & 0 & 0 \\
\hline \multirow[t]{6}{*}{ Week 21} & Much worse & $1(20 \%)$ & 0 \\
\hline & Minimally worse & $1(20 \%)$ & 0 \\
\hline & No change & $3(60 \%)$ & $5(83 \%)$ \\
\hline & Minimally improved & 0 & 0 \\
\hline & Much improved & 0 & $1(17 \%)$ \\
\hline & $\begin{array}{l}\text { Very much } \\
\text { improved }\end{array}$ & 0 & 0 \\
\hline \multirow{6}{*}{$\begin{array}{l}\text { Early withdrawal } \\
\text { during long-term } \\
\text { follow-up }\end{array}$} & Much worse & $1(100 \%)$ & $2(100 \%)$ \\
\hline & Minimally worse & 0 & 0 \\
\hline & No change & 0 & 0 \\
\hline & Minimally improved & 0 & 0 \\
\hline & Much improved & 0 & 0 \\
\hline & $\begin{array}{l}\text { Very much } \\
\text { improved }\end{array}$ & 0 & 0 \\
\hline
\end{tabular}

week 4; -72\%, week 13) (fig 2). Mean eosinophil numbers were also assessed by immunofluorescence: mean eosinophil numbers were significantly reduced in the mepolizumab group at weeks 4 $(-54 \%)$ and $13(-55 \%)$, but not in the placebo group, in which no reduction was observed (table 3 ). Eosinophil numbers also decreased in blood as a consequence of mepolizumab treatment. A marked and significant decrease was already seen at week 1 , and eosinophil numbers remained lowered through to the STFU assessment (week 21; 12 weeks after the last infusion) (fig 2). In contrast, eosinophil numbers in blood did not change in the placebo-treated patients. At week 43 (34 weeks after the last infusion), blood eosinophil numbers in the mepolizumab group had returned to the levels seen at baseline and there was no longer a difference compared with the placebo group (fig 2).

\section{Clinical efficacy}

The effect of mepolizumab on symptoms was assessed by calculating the proportion of days that subjects reported difficulty in swallowing averaged over the 7 days prior to the clinic visit and by ranking the global change of EoO symptoms compared with baseline. At baseline, mepolizumab-treated patients reported difficulty in swallowing food on $>90 \%$ of days compared with $75 \%$ of days for placebo-treated patients. In the mepolizumab group, two patients clearly improved and three patients did not change (fig 3, left panel). Overall, there was a $>20 \%$ improvement within the time period of weeks 913 that even increased up to $\sim 30 \%$ compared with baseline between weeks 13 and 17 (fig 3, right panel). In the placebo group, two patients improved, one had much less frequent dysphagia from the beginning and showed some variability over time, and three remained unchanged. When calculated as a

Table 5 Endoscopic eosinphilic oesophagitis abnormalities

\begin{tabular}{llll}
\hline Visit & Score & $\begin{array}{l}\text { Mepolizumab } \\
(\mathbf{n}=\mathbf{5}) \mathbf{n}(\%)\end{array}$ & $\begin{array}{l}\text { Placebo }(\mathbf{n}=\mathbf{6}) \mathbf{n} \\
(\%)\end{array}$ \\
\hline Baseline & Absent & 0 & 0 \\
& Minor & 0 & $1(17 \%)$ \\
& Moderate & $1(20 \%)$ & $2(33 \%)$ \\
Week 4 & Severe & $4(80 \%)$ & $3(50 \%)$ \\
& Absent & 0 & 0 \\
& Minor & 0 & $1(17 \%)$ \\
Week 13 & Moderate & $3(60 \%)$ & $3(50 \%)$ \\
& Severe & $2(40 \%)$ & $2(33 \%)$ \\
& Absent & 0 & 0 \\
& Minor & 0 & 0 \\
& Moderate & $4(80 \%)$ & $1(17 \%)$ \\
\hline
\end{tabular}


Figure 4 Eosinophil-derived neurotoxin (EDN), tumour necrosis factor $\alpha$ (TNF $\alpha)$ and eotaxin-3 expression in oesophageal epithelium of patients with eosinophilic oesophagitits before and after mepolizumab and placebo treatment, respectively, as determined by immunofluorescence analysis (EDN: $\times 160 ;$ TNF $\alpha$ and eotaxin-3: $\times 400$ ). The lower right corner of each panel shows a magnification. Representative results are shown. Quantitative analyses of these experiments are shown in table 6.

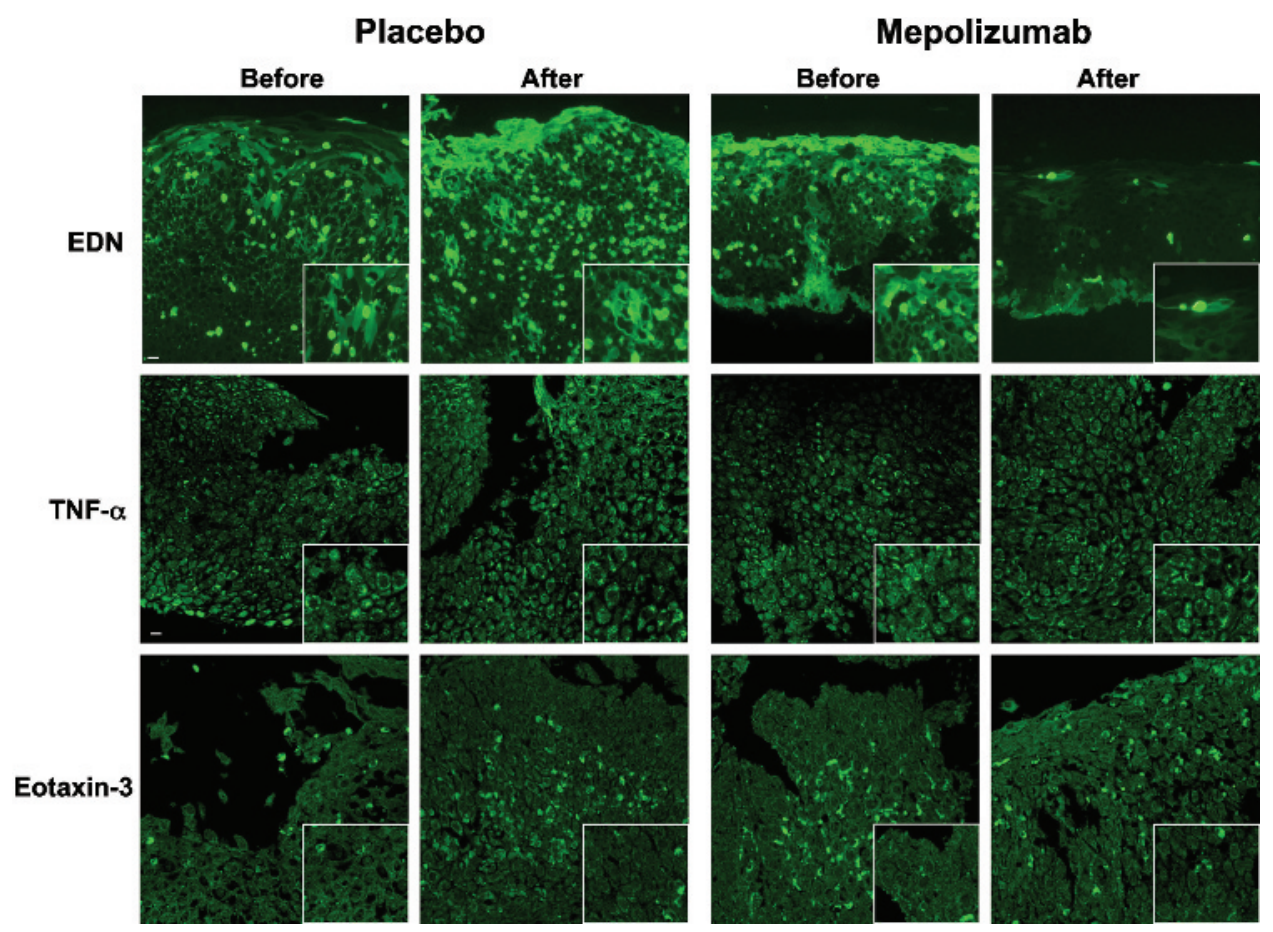

group, these patients also reported improvements, but to a lesser extent (20\% and 18\%, respectively).

The ranking of the global change of the EoO symptoms showed a similar tendency for clinical improvement in the mepolizumab group compared with the placebo group. At week 13, two patients of the mepolizumab group demonstrated much improvement, whereas in the placebo group only one patients showed minimal improvement (table 4). However, these marginal positive clinical effects were lost at week 21, although blood eosinophil numbers were still low at this time point (fig 2). It should be noted that, in those patients in which worsening was observed, symptoms appeared slowly and no flare-up was observed during the entire follow-up period after cessation of the mepolizumab treatment. There was one early withdrawal in the mepolizumab group and two in the placebo group, all due to worsening of EoO symptoms in the LTFU period (table 4).

Physical examination, standard blood haematology and chemistry analyses, and 12-lead ECGs were without any relevant abnormalities at baseline, apart from eosinophil levels, and no changes were observed during the entire study period.

\section{Endoscopic findings}

At baseline, the overall levels of the endoscopic abnormalities were graded in the mepolizumab group in four cases as severe and in one as moderate, whereas in the placebo group three were graded as severe, two as moderate and one as minor (table 5). At week 13, the corresponding gradation was one severe and four moderate in the mepolizumab group. In the placebo group, one was graded as severe and five as moderate (table 5). Individually, it appeared that three of five mepolizumab patients had improved (2 of these 3 also demonstrated improvement in dysphagia) and two showed no change. In the placebo group, two patients also showed some improvement ( 1 of these 2 patients also demonstrated improvement in dysphagia), three did not change and one worsened.

\section{Tissue biomarkers of inflammation}

Besides eosinophil numbers, we also analysed the extracellular deposition of one eosinophil granule protein, eosinophil-derived neurotoxin (EDN), as a marker of eosinophil activation. Both EDN-positive cells and extracellular EDN deposition were significantly less following mepolizumab treatment (fig 4; table 6). We also assessed the infiltration of inflammatory non-eosinophilic cells and the expression of inflammatory mediators previously implicated in EoO pathogenesis ${ }^{60}$ by immunofluorescence analysis. In contrast to eosinophils, the numbers of infiltrating mast cells (tryptase-positive cells) and $\mathrm{T}$ cells (CD3-positive cells) did not change (table 3, supplementary fig 2). All cytokines/chemokines preferentially expressed by eosinophils were significantly reduced, largely due to reduced eosinophil numbers in the mepolizumab but not in the placebo group. This was observed for all eotaxins (1, 2 and 3) and IL-5 that were each reduced by at least $60 \%$ at week 4 and remained at low levels at week 13 (table 6). Moreover, besides its presence in eosinophils, eotaxin-3 was also expressed by oesophageal epithelial cells, but the expression in these cells did not change in both treatment groups (fig 4; table 6). Similarly, tumour necrosis factor $\alpha$ (TNF $\alpha)$ was mainly expressed by epithelial cells, but no change of expression was seen as a consequence of either mepolizumab or placebo treatment (fig 4; table 6).

\section{Tissue biomarkers of remodeling}

Because eosinophils have been implicated in remodelling processes in both bronchial asthma ${ }^{31}$ and EoO, ${ }^{1032}$ we also assessed the expression of transforming growth factor $\beta 1$ (TGF $\beta 1$ ) and tenascin C in oesophageal tissues before and after mepolizumab and placebo treatment, respectively. In EoO specimens before treatment, we observed TGF $\beta 1$ expression, besides by eosinophils, mainly by epithelial cells and it appeared that the basal layers expressed less of this cytokine compared with the luminal layers. Immunoreactivity of tenascin $C$ was localised in both epithelial and subepithelial areas (fig 5). Both TGF $\beta 1$ and tenascin C expression by epithelial cells was slightly 
Table 6 Expression of soluble markers in oesophageal tissues

\begin{tabular}{|c|c|c|c|c|c|}
\hline & Visit & Mean & SD & $\begin{array}{l}\text { Change } \\
\text { from screen } \\
(\%)\end{array}$ & p Value \\
\hline \multicolumn{6}{|l|}{ Eotaxin- $1^{+}$cells per hpf } \\
\hline \multirow[t]{3}{*}{ Mepolizumab $(n=5)$} & Screening & 84.12 & 31.76 & & \\
\hline & Week 4 & 24.95 & 10.15 & -70 & 0.0001 \\
\hline & Week 13 & 20.89 & 13.91 & -75 & 0.0002 \\
\hline \multirow[t]{3}{*}{ Placebo $(n=6)$} & Screening & 49.47 & 21.47 & & \\
\hline & Week 4 & 42.83 & 27.27 & -13 & NS \\
\hline & Week 13 & 41.53 & 26.78 & -16 & NS \\
\hline \multicolumn{6}{|l|}{ Eotaxin- $2^{+}$cells per hpf } \\
\hline \multirow[t]{3}{*}{ Mepolizumab ( $\mathrm{n}=5$ ) } & Screening & 90.84 & 38.41 & & \\
\hline & Week 4 & 19.27 & 10.66 & -79 & 0.0001 \\
\hline & Week 13 & 23.45 & 20.65 & -74 & 0.0005 \\
\hline \multirow[t]{3}{*}{ Placebo $(n=6)$} & Screening & 58.99 & 29.41 & & \\
\hline & Week 4 & 47.13 & 28.15 & -20 & NS \\
\hline & Week 13 & 52.14 & 30.08 & -12 & NS \\
\hline \multicolumn{6}{|l|}{$\begin{array}{l}\text { Eotaxin- } 3^{+} \text {eosinophils per } \\
\text { hpf }\end{array}$} \\
\hline \multirow[t]{3}{*}{ Mepolizumab ( $n=5$ ) } & Screening & 62.63 & 38.48 & & \\
\hline & Week 4 & 14.63 & 6.31 & -77 & 0.0007 \\
\hline & Week 13 & 19.72 & 22.23 & -69 & 0.0041 \\
\hline \multirow[t]{3}{*}{ Placebo $(n=6)$} & Screening & 45.01 & 35.39 & & \\
\hline & Week 4 & 36.14 & 21.94 & -19 & NS \\
\hline & Week 13 & 39.19 & 32.63 & -13 & NS \\
\hline \multicolumn{6}{|l|}{$\begin{array}{l}\text { Eotaxin-3 expression by } \\
\text { epithelial cells (score) }\end{array}$} \\
\hline \multirow[t]{3}{*}{ Mepolizumab ( $(\mathrm{n}=5)$} & Screening & 1.2 & 1.4 & & \\
\hline & Week 4 & 1.5 & 1.7 & +25 & NS \\
\hline & Week 13 & 1.2 & 1.4 & 0 & NS \\
\hline \multirow[t]{3}{*}{ Placebo $(n=6)$} & Screening & 1.5 & 1.4 & & \\
\hline & Week 4 & 2.0 & 1.5 & +33 & NS \\
\hline & Week 13 & 1.75 & 1.5 & +17 & NS \\
\hline \multicolumn{6}{|l|}{ IL-5+ cells per hpf } \\
\hline \multirow[t]{3}{*}{ Mepolizumab $(n=5)$} & Screening & 72.17 & 43.79 & & \\
\hline & Week 4 & 28.87 & 18.53 & -60 & 0.006 \\
\hline & Week 13 & 29.91 & 27.31 & -59 & 0.004 \\
\hline \multirow[t]{3}{*}{ Placebo $(n=6)$} & Screening & 53.93 & 33.81 & & \\
\hline & Week 4 & 49.53 & 19.72 & -8 & NS \\
\hline & Week 13 & 48.61 & 27.29 & -10 & NS \\
\hline \multicolumn{6}{|l|}{$\begin{array}{l}\text { TNF } \alpha \text { expression by } \\
\text { epithelial cells (score) }\end{array}$} \\
\hline \multirow[t]{3}{*}{ Mepolizumab $(n=5)$} & Screening & 2.4 & 0.5 & & \\
\hline & Week 4 & 2.3 & 0.5 & -4 & NS \\
\hline & Week 13 & 2.3 & 0.5 & -4 & NS \\
\hline \multirow[t]{3}{*}{ Placebo $(n=6)$} & Screening & 2.5 & 0.6 & & \\
\hline & Week 4 & 2.25 & 0.6 & -10 & NS \\
\hline & Week 13 & 2.1 & 0.7 & -16 & NS \\
\hline $\begin{array}{l}\text { EDN expression by } \\
\text { eosinophils (score) }\end{array}$ & & & & & \\
\hline Mepolizumab $(n=5)$ & Screening & 1.80 & 0.45 & & \\
\hline & Week 4 & 1.25 & 0.44 & -31 & 0.0001 \\
\hline & Week 13 & 1.26 & 0.45 & -30 & 0.0001 \\
\hline Placebo $(n=6)$ & Screening & 1.66 & 0.38 & & \\
\hline & Week 4 & 1.24 & 0.62 & -25 & 0.006 \\
\hline & Week 13 & 1.64 & 0.66 & -1 & NS \\
\hline $\begin{array}{l}\text { Extracellular EDN } \\
\text { deposition (score) }\end{array}$ & & & & & \\
\hline Mepolizumab $(n=5)$ & Screening & 2.11 & 0.44 & & \\
\hline & Week 4 & 1.74 & 0.68 & -18 & 0.0073 \\
\hline & Week 13 & 1.65 & 0.17 & -22 & 0.0007 \\
\hline Placebo $(n=6)$ & Screening & 2.06 & 0.48 & & \\
\hline & Week 4 & 1.81 & 0.61 & -12 & NS \\
\hline & Week 13 & 2.01 & 0.46 & -2 & NS \\
\hline
\end{tabular}

EDN, eosinophil-derived neurotoxin; hpf, high power field; IL-5, interleukin-5; NS, nonsignificant; TNF $\alpha$, tumour necrosis factor $\alpha$. reduced at week 4, continued to decline, and reached statistical significance at week 13 in the mepolizumab but not in the placebo group (table 7 ).

\section{Blood biomarkers}

Both eosinophil cationic protein (ECP) and EDN levels significantly decreased in serum as a consequence of mepolizumab treatment at weeks 4, 9 and 13 (fig 6). In contrast, placebo had no effect on ECP and EDN levels. Interestingly, although eosinophil levels in blood were still low (fig 2), ECP levels increased 12 weeks after the last infusion in the mepolizumab group (STFU, week 21; fig 6). TNF $\alpha$ levels were not elevated at baseline and were always within the normal range throughout the study (data not shown). Moreover, IL-5 receptor $\alpha$ expression on blood eosinophils did not change in both groups (data not shown). Strikingly, a significant increase in eotaxin levels in blood was observed in the mepolizumab but not in the placebo group (fig 6).

\section{Safety}

Only few adverse events (in two patients in each group) were reported throughout the study as a whole; none was a serious adverse event. In the mepolizumab group, one patient had mild fatigue 1 day after the fourth infusion and another started an upper respiratory tract infection just prior to the fourth infusion; neither of these was considered to be related to mepolizumab (table 8). Of the placebo-treated patients, one experienced a 2-day episode of nausea and vomiting, and another had an oesophageal impaction. Mepolizumab was well tolerated. In particular, there were no clinical symptoms or signs of hypersensitivity or anaphylaxis. In the LTFU phase after week 21, three patients (two of the mepolizumab group, one in the placebo group) required alternative treatment for EoO.

Other than the changes in eosinophils and remodelling described, no clinically relevant changes in laboratory parameters were observed, with the exception of an elevation of bilirubin in one patient (male, aged 20 years) treated with mepolizumab from $13 \mu \mathrm{mol} / 1$ (normal range 0-22 $\mu \mathrm{mol} / \mathrm{l}$ ) at screening to 30, 34, 44 and $40 \mu \mathrm{mol} / \mathrm{l}$ at week 4, 9, 13 and 21, respectively. For pharmacokinetic and immunogenicity data of mepolizumab (supplementary tables 1 and 2), including methods and discussion, please consult the supplementary data.

\section{DISCUSSION}

EoO is a clearly defined, chronic inflammatory disorder of the oesophagus. Despite the rising incidence of $\mathrm{EoO}^{1-3}$ and the increased recognition by physicians, there are currently no approved medications for use in EoO; in part because no controlled clinical trials have been conducted. This phase I/II trial represents the first placebo-controlled study of treatment in adult EoO.

Based on our increased understanding of the pathogenesis that revealed similarities with those of asthma, ${ }^{63}$ it can be speculated that drugs used to treat asthma may also work in EoO. Although initial studies using anti-IL-5 antibodies to treat asthma were disappointing, ${ }^{34}{ }^{35}$ it was recently reported that patients suffering from eosinophilic asthma benefit from such a treatment. ${ }^{21} 22$ Experimental studies in mice additionally suggested that neutralising IL-5 might be a reasonable strategy to treat EoO. ${ }^{36}{ }^{37}$ Indeed, initial applications of mepolizumab within an open phase I/II trial comprising four adult patients with EoO were promising. ${ }^{23}$ Moreover, the eosinophil-stabilising agent montelukast has been used in an open trial and shown to 
Figure 5 Transforming growth factor $\beta 1$ (TGF $\beta 1$ ) and tenascin $C$ expression in oesophageal epithelium of patients with eosinophilic oesophagitis before and after mepolizumab and placebo treatment, respectively, as determined by immunofluorescence analysis $(\times 400)$. The lower right corner of the upper panels shows a magnification. Representative results are shown. Quantitative analyses of these experiments are shown in table 7. Note that the analysis of the subepithelial expression of tenascin $\mathrm{C}$ was not possible in the majority of the patients because of lack of tissue.

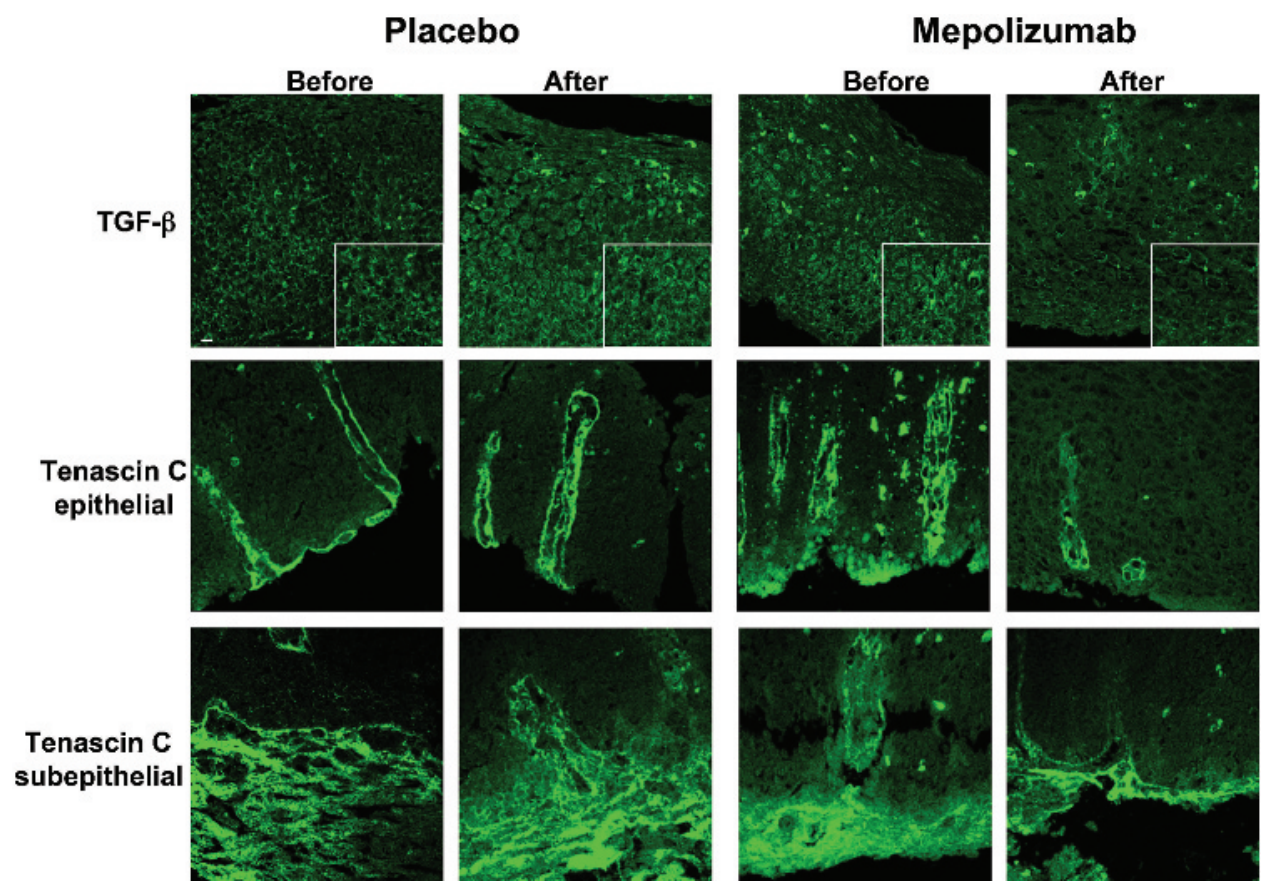

be clinically effective in at least a subgroup of patients, ${ }^{38}$ further supporting the view that targeting the eosinophil in EoO might be a successful treatment approach.

In contrast to the earlier open-label mepolizumab study, ${ }^{23}$ the patients in our study did not demonstrate obvious clinical improvements, although numbers of eosinophils were significantly reduced in both blood and oesophagus as a consequence of treatment. Whereas the decrease in blood eosinophils (up to 10-fold) was highly efficient and comparable with this previous study, the reduction of peak eosinophil numbers within the epithelial layer of the oesophagus was less successful (twofold to threefold in this study compared with sixfold in the earlier study). Fluticasone was reported to decrease eosinophil infiltration in paediatric EoO by $65.9 \%$ (proximal oesophagus) and $84.9 \%$ (distal oesophagus), respectively. ${ }^{16}$ On the other hand, infliximab was not associated with any antieosinophil or clinical effect. ${ }^{39}$ These findings suggest the possibility that tissue eosinophil depletion determines the clinical response of a given

Table 7 Expression of remodelling markers in oesophageal tissues

\begin{tabular}{clllll}
\hline & Visit & Mean & SD & $\begin{array}{l}\text { Change from } \\
\text { screen (\%) }\end{array}$ & p Value \\
\hline $\begin{array}{l}\text { TGFß1 expression by } \\
\text { epithelial cells (score) }\end{array}$ & & & & & \\
Mepolizumab ( $\mathrm{n}=5$ ) & Screening & 2.50 & 0.97 & & \\
& Week 4 & 2.00 & 0.82 & -20 & NS \\
& Week 13 & 1.70 & 0.67 & -32 & 0.0500 \\
Placebo ( $\mathrm{n}=6$ ) & Screening & 2.50 & 0.79 & & \\
& Week 4 & 3.08 & 0.51 & +23 & NS \\
Tenascin C expression in & Week 13 & 3.00 & 0.43 & +20 & NS \\
epithelial cell layer (score) & & & & & \\
Mepolizumab ( $\mathrm{n}=5$ ) & Screening & 3.00 & 1.05 & & \\
& Week 4 & 1.50 & 0.85 & -50 & 0.0057 \\
& Week 13 & 1.40 & 0.52 & -53 & 0.0021 \\
Placebo ( $\mathrm{n}=6$ ) & Screening & 1.67 & 1.07 & & \\
& Week 4 & 2.08 & 0.90 & +25 & n.s. \\
& Week 13 & 2.33 & 0.89 & +40 & n.s. \\
\hline
\end{tabular}

NS, non-significant; TGF $\beta 1$, transforming growth factor $\beta 1$. patient. Future studies involving more patients with EoO may prove or disprove this hypothesis by correlating the rate of depletion of tissue eosinophils with the clinical response.

In the absence of a validated EoO activity index, it is reasonable to take the hallmark of $\mathrm{EoO}$, the prominent eosinophilic infiltration of the oesophagus, as a primary end point in current therapeutic trials. In this study, we meticulously analysed by conventional histology and immunofluorescence analysis both peak and mean eosinophil numbers within the epithelial cell layer of the oesophagus. As assessed by histology, mepolizumab reduced oesophageal eosinophils approximately threefold, no matter whether we analysed peak or mean numbers. However, we noted the following differences between these two different approaches of counting. (1) Although peak eosinophil numbers were on average the same between the mepolizumab and the placebo group, both groups differed regarding their mean levels before treatment (the placebo group had $\sim 25 \%$ fewer eosinophils on average). (2) The peak eosinophil numbers differed more than the mean eosinophil numbers within the placebo group during the course of this study. In particular, the mean eosinophil numbers as assessed by immunofluorescence (ECP-positive cells) did not change at all in the placebo group over time, suggesting that this marker is robust and therefore suitable for the determination of the general "eosinophil load" of the oesophagus in patients with EoO. Having such a marker seems to be highly important, since the pattern of eosinophilic infiltration in the oesophagus can be patchy or segmental in EoO. ${ }^{24}$

The reduction of the "eosinophil load" of the oesophagus by mepolizumab as assessed by immunofluorescence analysis was twofold and consistently observed in each of the five patients. This observation is in line with previous reports, which observed a twofold reduction in eosinophil numbers in bronchial ${ }^{40}$ and skin ${ }^{19}$ tissues after anti-IL-5 antibody treatment. It should be noted that all ongoing treatments for EoO were discontinued during the screening period, meaning that patients were left without any antieosinophil treatment, in contrast to the previous open EoO trial with mepolizumab where the patients continued their previous treatment. Three of the four 
$\underset{[\mathrm{ng} / \mathrm{ml}]}{\mathrm{ECP}}$

Placebo

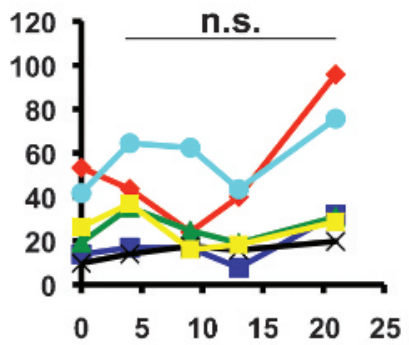

EDN

[ng/ml]

n.s.

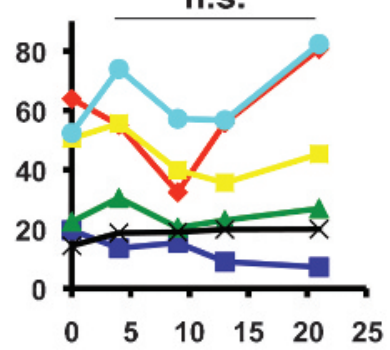

Eotaxin [pg/ml]

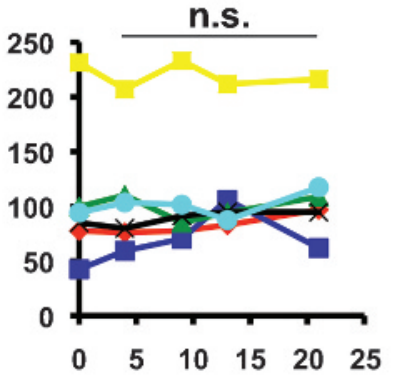

$\multimap$ Patient 1

-Patient 2

-Patient 3

-Patient 4

Patient 5

- Patient 6

\section{Mepolizumab}

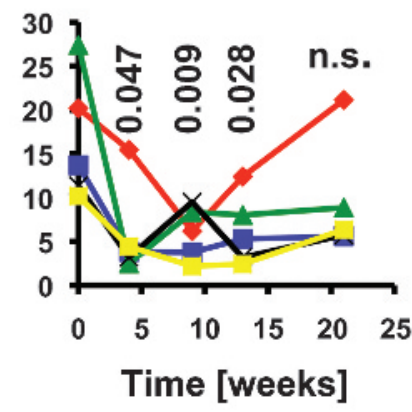

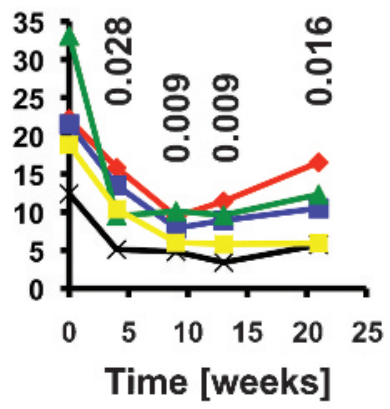

Figure 6 Changes in serum eosinophil cationic protein (ECP), eosinophil-derived neurotoxin (EDN) and eotaxin concentrations by mepolizumab in patients with eosinophilic oesophagitis. Single patient data are presented in both the placebo (upper panels) and mepolizumab (lower panels) groups. $p$ Values are indicated.

EoO patients in this earlier study had topical fluticasone treatment. ${ }^{23}$ It is possible that concurrent topical corticosteroid treatment increases the potency of mepolizumab-mediated eosinophil depletion in the oesophagus, resulting in a greater clinical benefit than from either of these treatments alone. Moreover, since anti-TNF $\alpha$ antibody treatment was also reported not to be effective in patients with $\mathrm{EoO},{ }^{39}$ it is possible that targeting a single molecule may prove insufficient to control symptoms and disease progression optimally, at least in adult EoO. However, it is also possible that the selection of topical corticosteroid-refractory patients in this study had a negative impact on the clinical results. On the other hand, immunomodulators such as antibodies could be an option for patients not responding to standard treatments such as corticosteroids.

While we did not observe increases in IL-5 receptor $\alpha$ expression on eosinophils in association with mepolizumab treatment, ${ }^{41}$ we noticed a significant increase of eotaxin levels in blood as a consequence of mepolizumab treatment. The source of increased eotaxin production does not appear to be the oesophagus where we observed decreased eotaxin levels

Table 8 Adverse events

\begin{tabular}{lll}
\hline Adverse event & Mepolizumab (n=5) n (\%) & Placebo (n=6) n (\%) \\
\hline Any adverse event & $2(40)$ & $2(33)$ \\
Nausea & 0 & $1(17)$ \\
Oesophageal food impaction & 0 & $1(17)$ \\
Vomiting & 0 & $1(17)$ \\
Fatigue & $1(20)$ & 0 \\
Upper respiratory tract & $1(20)$ & 0 \\
infection & &
\end{tabular}

following antibody treatment. It is possible that eotaxin is, at least partially, responsible for the rebound effect, which has been observed after anti-IL-5 antibody dose reduction. ${ }^{42}$

One of the main treatment goals in EoO, apart from the relief of symptoms, is the prevention of long-term damage of the affected organ. Recently, it was demonstrated that IL-5-induced eosinophilia leads to oesophageal remodelling, ${ }^{10}$ so reducing IL5 -induced eosinophilia should decrease the remodelling process. Although the "eosinophil load" was only moderately reduced by mepolizumab, we observed reduced tenascin C and TGF $\beta 1$ expression in the epithelial layer of the oesophagus in these patients that was not observed in the placebo group. These data are in agreement with the current view that eosinophils regulate tissue remodelling processes both in asthma ${ }^{31}$ and in EoO. ${ }^{9} 1032$ It remains, however, unclear whether such early molecular remodelling changes result in fewer macroscopic signs of obstruction (strictures and rings). Within the short observation period of this study, no marked changes of endoscopic features were observed following mepolizumab treatment. Clearly, studies with a longer duration of treatment may allow for better assessment and characterisation of remodelling.

As observed in previous studies, mepolizumab was well tolerated. One patient developed antibodies against mepolizumab at week 27 (18 weeks after the last infusion). Whether such antibodies neutralise the pharmacodynamic activity of mepolizumab remains to be investigated in future studies involving more patients.

Taken together, we report the first placebo-controlled study analysing the efficacy of an IL-5 blockade in adult patients with active EoO. The results show that mepolizumab, administered as four infusions over 3 months in the absence of any other concurrent antieosinophil treatment, is not able to induce a 
resolution of the eosinophil tissue infiltration and to reduce markedly the resulting symptoms. However, this mepolizumab regimen did reduce the mean "eosinophil load" of the oesophagus by twofold which resulted in molecular signs of reduced oesophageal remodelling. Further larger and perhaps longer controlled studies using mepolizumab in combination with other antieosinophil treatments are needed to develop therapeutic options for patients with severe, refractory EoO.

Acknowledgements: We are grateful to Manuela Studer and Alexandra Sobh for excellent technical support. The laboratory of HUS is supported by the Swiss National Science Foundation (grant no. 310000-107526).

Funding: This study was supported by GlaxoSmithKline (GSK), Greenford, UK. The trial was conducted under GSK protocol number MEE103226.

Competing interests: Declared (the declaration can be viewed on the Gut website at http://www.gut.bmj.com/supplemental).

Ethics approval: The study was conducted according to ICH/GCP guidelines and was approved by the Ethics Committee of the Kantonsspital Olten, Olten, and the Swissmedic regulatory authority, Bern, Switzerland.

Contributors: The study was planned and designed by AS, MB and HUS. Data collection and analysis was performed by the authors, who took final responsibility for manuscript content and the decision to submit for publication. AS, MB and HUS wrote the manuscript.

Provenance and peer review: Not commissioned; externally peer reviewed.

\section{REFERENCES}

1. Noel RJ, Putnam PE, Rothenberg ME. Eosinophilic esophagitis. N Engl J Med 2004;351:940-1.

2. Straumann A, Simon HU. Eosinophilic esophagitis: escalating epidemiology? J Allergy Clin Immunol 2005;115:418-9.

3. Chehade M, Sampson HA. Epidemiology and etiology of eosinophilic esophagitis. Gastrointest Endosc Clin N Am 2008;18:33-44.

4. Furuta GT, Liacouras CA, Collins MH, et al. Eosinophilic esophagitis in children and adults: a systematic review and consensus recommendations for diagnosis and treatment. Gastroenterology 2007;133:1342-63.

5. Spechler SJ, Genter RM, Souza RF. Thoughts on the complex relationship between gastroesophageal reflux disease and eosinophilic esophagitis. Am J Gastroenterol 2007; 102:1301-6.

6. Straumann A, Bauer M, Fischer B, et al. Idiopathic eosinophilic esophagitis is associated with a Th2-type allergic inflammatory response. J Allergy Clin Immunol 2001;108:954-61.

7. Simon D, Marti HP, Heer P, et al. Eosinophilic esophagitis is frequently associated with IgE-mediated allergic airway diseases. J Allergy Clin Immunol 2005;115:1090-2.

8. Furuta GT, Straumann A. The pathogenesis and management of eosinophilic esophagitis. Aliment Pharmacol Ther 2006;24:173-82.

9. Straumann A, Spichtin HP, Grize L, et al. Natural history of primary eosinophilic esophagitis: a follow-up of 30 adult patients for up to 11.5 years. Gastroenterology 2003;125:1660-9.

10. Mishra A, Wang M, Pemmaraju VR, et al. Esophageal remodelling develops as a consequence of tissue specific IL-5-induced eosinophilia. Gastroenterology 2008:134:204-14.

11. Liacouras CA, Wenner WJ, Brown K, et al. Primary eosinophilic esophagitis in children: successful treatment with oral corticosteroids. J Pediatr Gastroenterol Nutr 1998:26:380-5.

12. Faubion WA, Perrault J, Burgart LJ, et al. Treatment of eosinophilic esophagitis with inhaled corticosteroids. J Pediatr Gastroenterol Nutr 1998;27:90-3.

13. Teitelbaum JE, Fox VL, Twarog FJ, et al. Eosinophilic esophagitis in children: immunopathological analysis and response to fluticasone propionate. Gastroenterology 2002:122:1216-25.

14. Arora AS, Perrault J, Smyrk TC. Topical corticosteroid treatment of dysphagia due to eosinophilic esophagitis in adults. Mayo Clin Proc 2003;78:830-5.
15. Noel RJ, Putnam PE, Collins MH, et al. Clinical and immunopathologic effects of swallowed fluticasone for eosinophilic esophagitis. Clin Gastroenterol Hepatol 2004;2:568-75

16. Konikoff MR, Noel RJ, Blanchard C, et al. A randomized, double-blind, placebocontrolled trial of fluticasone propionate for pediatric eosinophilic esophagitis. Gastroenterology 2006;131:1381-91.

17. Schaefer ET, Fitzgerald JF, Molleston JP, et al. Comparison of oral prednisone and topical fluticasone in the treatment of eosinophilic esophagitis: a randomized trial in children. Clin Gastroenterol Hepatol 2008;6:165-73.

18. Rothenberg ME, Klion AD, Roufosse FE, et al. Treatment of patients with the hypereosinophilic syndrome with mepolizumab. N Engl J Med 2008;358:1215-28.

19. Plötz SG, Simon HU, Darsow U, et al. Use of an anti-interleukin-5 antibody in the hypereosinophilic syndrome with eosinophilic dermatitis. $N$ Engl J Med 2003;349:2334-9

20. Gevaert $\mathbf{P}$, Lang-Loidolt D, Lackner A, et al. Nasal IL-5 levels determine the response to anti-IL-5 treatment in patients with nasal polyps. J Allergy Clin Immunol 2006;118:1133-41.

21. Haldar P, Brightling CE, Hargadon B, et al. Mepolizumab and exacerbations of refractory eosinophilic asthma. N Engl J Med 2009;360:973-84.

22. Nair P, Pizzichini MM, Kjarsgaard M, et al. Mepolizumab for prednisone-dependent asthma with sputum eosinophilia. N Engl J Med 2009;360:985-93

23. Stein ML, Collins MH, Villanueva JM, et al. Anti-IL-5 (mepolizumab) therapy for eosinophilic esophagitis. J Allergy Clin Immunol 2006;118:1312-9.

24. Gonsalves N, Policarpio-Nicolas M, Zhang 0 , et al. Histopathologic variability and endoscopic correlates in adults with eosinophilic esophagitis. Gastrointest Endosc 2006:64:313-9.

25. Horie S, Gleich GJ, Kita H. Cytokines directly induce degranulation and superoxide production from human eosinophils. J Allergy Clin Immunol 1996;98:371-81.

26. Simon D, Hösli S, Kostylina G, et al. Anti-CD20 (rituximab) treatment improves atopic eczema. J Allergy Clin Immunol 2008;121:122-8.

27. Yousefi S, Gold JA, Andina N, et al. Catapult-like release of mitochondrial DNA by eosinophils contributes to antibacterial defense. Nat Med 2008;14:949-53.

28. Perez GL, Peter MS, Reda AM, et al. Mast cells, neutrophils, and eosinophils in prurigo nodularis. Arch Dermatol 1993;129:861-5.

29. Mire-Sluis AR, Barrett YC, Devanarayan V, et al. Recommendations for the design and optimization of immunoassays used in the detection of host antibodies against biotechnology products. J Immunol Methods 2004;289:1-16.

30. Blanchard C, Wang N, Stringer KF, et al. Eotaxin-3 and a uniquely conserved geneexpression profile in eosinophilic esophagitis. J Clin Invest 2006;116:536-47.

31. Flood-Page $\mathbf{P}$, Menzies-Gow A, Phipps S, et al. Anti-IL-5 treatment reduces deposition of ECM proteins in the bronchial subepithelial basement membrane of mild atopic asthmatics. J Clin Invest 2003;112:1029-36.

32. Aceves SS, Newbury RO, Dohil R, et al. Esophageal remodelling in pediatric eosinophilic esophagitis. J Allergy Clin Immunol 2007;119:206-12.

33. Straumann A, Simon D, Simon HU. Eosinophilic esophagitis: new pathogenic insights. Curr Immunol Rev 2005;1:297-304

34. Leckie MJ, ten Brincke $A$, Khan J, et al. Effects of an interleukin-5 blocking monoclonal antibody on eosinophils, airway-responsiveness, and the late asthmatic response. Lancet 2000;356:2144-8.

35. Kips JC, O'Connor BJ, Langley SJ, et al. Effect of SCH55700, a humanized antihuman interleukin- 5 antibody, in severe persistent asthma: a pilot study. Am J Respir Crit Care Med 2003;167:1655-9.

36. Mishra A, Hogan SP, Brandt EB, et al. An etiological role for aeroallergens and eosinophils in experimental esophagitis. J Clin Invest 2001:107:83-90.

37. Mishra A, Hogan SP, Brandt EB, et al. IL-5 promotes eosinophil trafficking to the esophagus. J Immunol 2002:168:2464-9.

38. Attwood SEA, Lewis CJ, Bronder CS, et al. Eosinophilic oesophagitis: a novel treatment using Montelukast. Gut 2003;52:181-5.

39. Straumann A, Bussmann C, Conus $S$, et al. Anti-TNF- $\alpha$ (infliximab) therapy for severe eosinophilic esophagitis. J Allergy Clin Immunol 2008;122:425-7.

40. Flood-Page PT, Menzies-Gow AN, Kay AB, et al. Eosinophil's role remains uncertain as anti-interleukin-5 only partially depletes numbers in asthmatic airway. Am J Respir Crit Care Med 2003;167:199-204.

41. Stein ML, Villanueva JM, Buckmeier BK, et al. Anti-IL-5 (mepolizumab) therapy reduces eosinophil activation ex vivo and increases IL-5 and IL-5 receptor levels. J Allergy Clin Immunol 2008;121:1473-83.

42. Kim YJ, Prussin C, Martin B, et al. Rebound eosinophilia after treatment of hypereosinophilic syndrome and eosinophilic gastroenteritis with monoclonal anti-IL-5 antibody SCH55700. J Allergy Clin Immunol 2004;114:1449-55. 